\title{
HIGHLY SELECTIVE TRANSPORT OF MERCURY(II) ION THROUGH A BULK LIQUID MEMBRANE
}

\author{
Ardeshir Shokrollahi* and Mehrorang Ghaedi \\ Department of Chemistry, Yasouj University, Yasouj, 75918-74831 Iran \\ Mojtaba Shamsipur \\ Department of Chemistry, Razi University, Kermanshah - Iran
}

Recebido em 25/3/08; aceito em 8/8/08; publicado na web em 18/12/08

\begin{abstract}
In this work carrier-facilitated transport of mercury(II) against its concentration gradient from aqueous $0.04 \mathrm{M}$ hydrochloric acid solution across a liquid membrane containing isopropyl 2-[(isopropoxycarbothiolyl)disulfanyl]ethane thioate (IIDE) as the mobile carrier in chloroform has been investigated. Sodium thiocyanate solution $(1.6 \mathrm{M})$ was the most efficient receiving phase agent among several aqueous reagents tested. Various parameters such as investigated. Under optimum conditions the transport of $\mathrm{Hg}$ (II) across the liquid membrane is more than $97 \%$ after $2.5 \mathrm{~h}$. The carrier, IIDE, selectively and efficiently could able to transport $\mathrm{Hg}$ (II) ions in the presence of other associated metal ions in binary systems.
\end{abstract}

Keywords: bulk liquid membrane; mercury (II) ion; isopropyl 2-[(isopropoxycarbothiolyl)disulfanyl]ethane thioate.

\section{INTRODUCTION}

The toxic effects of mercury are well known. Mercury may enter a human body by inhalation of mercury vapor [mainly in the form of $\mathrm{Hg}(0)$ ], drinking water (mainly as inorganic mercury, $\mathrm{Hg}^{2+}$ ), and/ or by the consumption of fish and fish products (mainly as methylmercury, $\mathrm{CH}_{3} \mathrm{Hg}^{2+}$ in the diet). ${ }^{1}$

Mercury and its compounds even at low concentrations are known to be a very dangerous neurotoxin for living organisms. Cold vapor atomic absorption spectrometry (CVAAS) with the typical detection limit of $0.05 \mathrm{mg} \mathrm{L}^{-1}$ level due to its advantages including simplicity, high sensitivity, and freedom from interference. is one of the most selective, sensitive, and popular techniques for mercury(II) determination in a wide variety of samples. The determination of traces of mercury ion at the sub $\mathrm{ng} \mathrm{mL}^{-1}$ level even using sensitive CVAAS usually requires a prior separation and/or preconcentration step in order to improve method sensitivity with separation of target compounds as well as minimization of the matrix effects. Selective separation of a given metal ion from a complex mixture of other ionic species is of increasing importance in industrial and analytical chemistry and separation sciences. In most cases, before detection, various interfering species must be removed and/or the species of interest must be enriched.

Numerous extraction and separation methods for mercury determination have been developed., ${ }^{2,3}$ Liquid membrane transport mediated with a mobile carrier has been proposed as a promising technology for separation and purification of various metal ions. Liquid membranes (liquid phases), existing in either supported or unsupported form, serve as selective barriers between liquid or gas phases and have shown great potential and application in separations.

Selective transport of cationic substrates by membrane carriers is of great importance in chemistry, biology, and separation sciences. Compared with conventional separation processes such as liquidliquid extraction, membrane techniques are characterized by the technical simplicity and high efficiency in separating or enriching material from gaseous or liquid mixtures. Also, these methods reduce the solvent inventory requirements and also allows the use of

*e-mail: ashokrollahi@mail.yu.ac.ir expensive and highly selective extractant which otherwise would be uneconomic in solvent extractions.

Bulk liquid membrane (BLM) is one of the simple, lowest and efficient types of liquid membranes. ${ }^{4,5}$ In this technique similar to liquid membrane configurations, (viz ion transport across membranes) combine the extraction, diffusion, and back extraction of analytes are particularly drawing maximum attention. ${ }^{6}$ BLM constitute the cheapest separation techniques because of their relatively small inventory and low capital cost.

In a BLM, a relatively thick layer of immiscible fluid is used to separate the source and receiving phase. There is no means of support for the membrane phase and it is kept apart from the external phases only by means of its immiscibility. A recent development in liquid membranes is the incorporation of selective carriers within the liquid membrane phase which selectivity and efficiency via chemical reaction facilitate the transport of a specific compound across the membrane.

Carrier mediated transport through liquid membrane is well known as one of the most powerful tools for such concentration, separation and recovery of target compound. The selective transport of metal ions across a membrane is known to play an essential role in many biological processes. ${ }^{7}$ There has been a growing interest in the transport of metal ions mediated by receptor molecules where the carrier operates selective across artificial or biological membranes.

In this regard, there has been considerable interest in the use of proton ionizable carriers for the transport of metal cations between two aqueous solutions through an organic membrane. ${ }^{8}$ These $\mathrm{pH}$-regulated ligands described until now present the fact that transfer of the counter-anion from the aqueous phase into the organic medium is avoided. Such chelating agents do not involve concomitant transfer of one or more aqueous phase anions into the organic medium. This factor was of immense importance to potential applications in which hard aqueous phase anions such as chloride, nitrate and sulfate would be involved.

Transport of mercury through liquid membranes using various carriers such as polybutadiene, ${ }^{9}$ triisobutylphosphate (TBP), ${ }^{10} 18$-crown-6 and 21-crown-7, ${ }^{11}$ bis (di (2-ethylhexyloxy)) thiophosphoryl) disulfide $^{12}$ have been carried out. The present paper describes the use of isopropyl 2-[(isopropoxycarbothiolyl) disulfanyl] ethane thioate (IIDE) as a selective neutral carrier for $\mathrm{Hg}^{2+}$ ion transport through 
a bulk liquid membrane. For this purpose the influence of effective parameters such as stirring rate, concentration of $\mathrm{HCl}$ in the source phase, concentration of $\mathrm{NaSCN}$ in the receiving phase, concentration of IIDE in the membrane and contact time was optimized.

\section{EXPERIMENTAL}

\section{Reagents}

A stock solution of $\mathrm{Hg}$ (II) was prepared by dissolving an appropriate and accurately amount of mercuric chloride of analytical regent grade in $1 \%(\mathrm{v} / \mathrm{v}) \mathrm{HCl}$ solution. The working standard solution was prepared by further diluting the stock solution with doubly distilled deionized water. $\mathrm{SnCl}_{2}$ and Nitrate salts of all other cations used were of the analytical grade and used without further purification. Doubly distilled deionized water was used throughout. Extra pure chloroform purchased from Merck was used as organic phase. (Merck E. Dermstant Germany)

\section{Synthesis of IIDE}

Iodine (1 mmol) in $\mathrm{CH}_{2} \mathrm{Cl}_{2}(10 \mathrm{~mL})$ was added to a stirred solution of potassium o-isopropyl(dithiocarboma( $1 \mathrm{mmol}$ ) in $\mathrm{CH}_{2} \mathrm{Cl}_{2}(10$ $\mathrm{mL}$ ) and stirred for $1 \mathrm{~h}$. The reaction mixture was washed with $10 \%$ $(\mathrm{w} / \mathrm{v})$ aqueous $\mathrm{Na}_{2} \mathrm{~S}_{2} \mathrm{O}_{3}(1 \times 10 \mathrm{~mL})$ and $\mathrm{H}_{2} \mathrm{O}(2 \times 10 \mathrm{~mL})$. The organic layer was dried over $\mathrm{MgSO}_{4}$ and evaporated under reduced pressure. More purification was achieved by re-crystallization in hexane, so that, pale yellow crystals of IIDE were obtained in $90 \%$ yield $(0.24$ $\mathrm{g})$. The structure and purity of IIDE was confirmed by elemental analysis, NMR and IR spectroscopy. $1 \mathrm{H} \mathrm{NMR}\left(\mathrm{CCl}_{4}\right) . \delta(\mathrm{ppm}): 1.43$ (t, 12H, CH3), 5.63 (m, 2H, CH). IR (KBr). v max ( $\left.\mathrm{cm}^{-1}\right)$ : $2979.8(\mathrm{~s})$, 2869.9 (w), 1463.9 (s), 1442.7 (s), 1373.0 (s), 1271.1 (s, b), 1145.6 (s), 1082.2 (s), 1048.0 (s, b) 898.8 (s), 796. 5 (s), 690. 5 (m). The structure of IIDE is presented in Scheme 1.

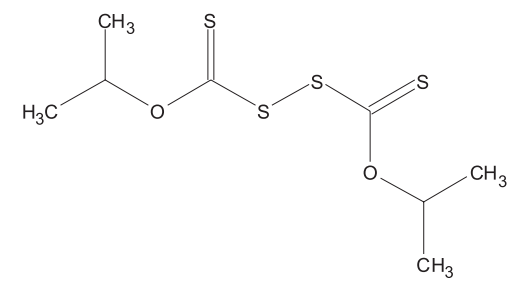

Scheme 1. Structure of IIDE

\section{Apparatus}

The determination of mercury content was carried out with a Shimadzu AA-670 atomic absorption spectrometer equipped with an Hg-hollow cathode lamp (HCL) and an on-line cold vapor generation system using $\mathrm{SnCl}_{2}$. The wavelength was set at $253.7 \mathrm{~nm}$ (resonance line) with the spectral bandwidth of $0.5 \mathrm{~nm}$. A long path quartz cell ( $2 \mathrm{~cm}$ i.d., $10 \mathrm{~cm}$ long) connected to the spectrometer was used as a detection system. The determination of all other cations was carried out with a Shimadzu AA-670 atomic absorption spectrometer under recommended conditions for each metal ion. A digital $\mathrm{pH}$ meter, Metrohm model 632 equipped with a combined glass calomel electrode was used for the $\mathrm{pH}$ adjustments. A bulk type liquid membrane cell ${ }^{13}$ (Figure 1) was used in this study. All conductance measurements were carried out with a Metrohm 712 conductivity meter with a dip-type conductivity cell made of platinum black.

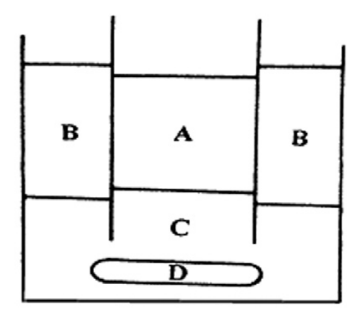

Figure 1. Representation of the bulk type liquid membrane cell used, (A) source phase; $(B)$ receiving phase; $(C)$ membrane phase; $(D)$ magnetic stirrer

\section{Procedure}

All transport experiments were carried out at ambient temperature. A cylindrical glass cell (Figure 1) (inside diameter, $4.0 \mathrm{~cm}$ ) holding a glass tube (inside diameter, $2.0 \mathrm{~cm}$ ) which separates the two aqueous phases, was used. The inner aqueous phase (source phase, SP) contained mercuric chloride $\left(5 \mathrm{~mL}, 2.0 \times 10^{-5} \mathrm{M}\right)$ and $0.04 \mathrm{M}$ hydrochloric acid, while the outer aqueous phase (receiving phase, RP) contained sodium thiocyanate $(10 \mathrm{~mL}, 1.6 \mathrm{M})$. The membranes phase (MP) is compromised of $20 \mathrm{~mL}$ of $6.0 \times 10^{-3} \mathrm{M}$ IIDE in chloroform below these aqueous phases and bridged the two aqueous phases. The organic layer was magnetically stirred by a Teflon-coated magnetic bar $(2.0 \times 5 \mathrm{~cm}$, diameter $)$. Under these conditions, while is the mixing process perfect, the interfaces between the organic membrane and the two aqueous phases remained flat and well defined. Determination of the mercury ion concentration in both aqueous phases was carried out by CV-AAS. A similar transport experiment was carried out in the absence of the carrier for reference.

\section{Conductometric titration}

In this experiment, $15 \mathrm{~mL}$ of the $\mathrm{Hg}^{2+}$ ion solution $\left(2.0 \times 10^{-5} \mathrm{M}\right)$ was placed in the titration cell thermostated to $25.0 \pm 0.1{ }^{\circ} \mathrm{C}$ by a home made thermostat and the conductance of the solution was measured. Then, several increments of IIDE solution using a precalibrated microsyring was added. The conductance of the solution was measured after each addition. The stability constants of the resulting complex was evaluated from the computer fitting of the molar conductancemole ratio data to the corresponding equations according our previous publication using the program KINFIT. ${ }^{14}$

\section{RESULTS AND DISCUSSION}

IIDE as a sulfur containing ligand is insoluble in water. Due to the existence of four donating sulfur atoms in the flexible structure of IIDE based on the well known hard-soft acid-base theory, ${ }^{15-17}$ it was expected that the stability of its complex with $\mathrm{Hg}^{2+}$ ion be higher than the other ions including alkali, alkaline earth and many transition and heavy metal ions.

\section{Conductometric investigation of complexation of $\mathrm{Hg}^{2+}$ ion with IIDE}

In preliminary experiments in order to obtain useful information about the stoichiometry and stability of the complexation of IIDE with $\mathrm{Hg}^{2+}$ ion, the system was investigated conductometrically in acetonitrile solution. It is obvious from Figure 2 that a distinct inflection point at $\mathrm{L} / \mathrm{Hg}^{2+}$ molar ratio of $1: 1$ were occurred. The obtained stability constant for $\mathrm{Hg}$-IIDE complex using KINFIT program is $7.94 \times 10^{5}$. 


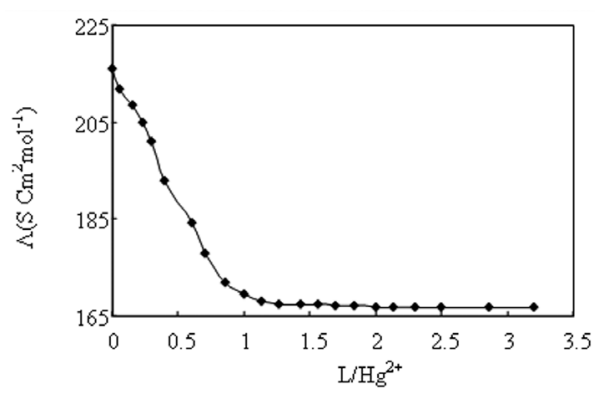

Figure 2. Mole ratio plot of conductometric titration of $\mathrm{Hg}^{2+}(0.002 \mathrm{mM})$ with IIDE in acetonitrile solution at $T=25 \pm 0.1$

The resulting positive charged complex can form an ion pair with an appropriate anion. The neutral form ion pair can be quantitatively extracted into a suitable organic solvent. Our preliminary experiments clearly revealed that the IIDE dissolves easily in chloroform and because of low immiscibility of this solvent with water and its higher density than water; we chose it for membrane phase. Thus, in this work, we were interested to investigate the transport behavior of $\mathrm{Hg}^{2+}$ ion through a liquid membrane containing IIDE as a potential ion carrier and choloride as a companion anion. As expected, the nature of the ligand used as carrier in the organic membrane phase has a very significant effect on the efficiency and selectivity of $\mathrm{Hg}^{2+}$ ion transport.

Primary results showed that this membrane could transport the $\mathrm{Hg}^{2+}$ ion selectively among other metal ions. Using acidic medium in source phase uphill transport was achieved, while in basic receiving phase no transport efficiency was observed. In order to increase the efficiency and selectivity of transport, a particular agent in the receiving phase must been used. One of the interesting possibilities for this purpose was the use of thiocyanate ion. Finally the experimental variables must be optimized in order to achieve the highest efficiency and selectivity in the transport of $\mathrm{Hg}^{2+}$ ions across the membrane in short time.

\section{Influence of condition of source phase on $\mathrm{Hg}^{2+}$ ion transport}

Most chelating ligands are conjugate bases of weak acid groups and accordingly, have a very strong affinity for hydrogen ions. Therefore the $\mathrm{pH}$, play an important role in the complexation of metal ions by chelation. The $\mathrm{pH}$ will determine the values of the conditional stability constants of the complexes of metal ions with a desired ligand. Due to the presence of a sulfur atom in the structure of IIDE it is expected that the of its complexation ability is sensitive to $\mathrm{pH}$.

It was expected that the efficiency of transport at higher $\mathrm{pH}$ values $(>2.0)$ due to the formation of $\mathrm{Hg}(\mathrm{OH})_{2}(\mathrm{~s})$ precipitate (white precipitate) at top of the chloroform between the source and membrane phases has been reduced. Therefore the source phase must be acidic.

The effect of the presence of $0.1 \mathrm{M}$ of different acids including picric acid, $\mathrm{HCl}, \mathrm{HClO}_{4}, \mathrm{HNO}_{3}$ and $\mathrm{H}_{2} \mathrm{SO}_{4}$ in the source phase on the transport of $\mathrm{Hg}^{2+}$ ion was studied and it was observed that the maximum transport occurs in the presence of $0.1 \mathrm{M} \mathrm{HCl}$. It was found that nitrate ion is not a suitable counter anion to accompany the $\mathrm{Hg}^{2+}-\mathrm{IIDE}$ complex into the organic phase and only $30 \%$ of $\mathrm{Hg}^{2+}$ ions was transported into the receiving phase in a long time. The transport efficiency was increased to $45 \%$ in the presence of perchlorate ion (4 h) in source phase, while addition of picric acid to the source phase increase the transport efficiency of $\mathrm{Hg}^{2+}$ but not quantitatively. In the presence of hydrochloric acid in the source the percentage of $\mathrm{Hg}^{2+}$ ion transported to receiving phase quantitatively was increased.
The transport efficiency of $\mathrm{Hg}^{2+}$ ion was also found to be dependent on the concentration of $\mathrm{HCl}$ in the SP (Figure 3). Maximum transport occurs at $\mathrm{HCl}$ concentration range of 0.01-0.1 M, while further transport studies of $\mathrm{Hg}^{2+}$ ion was carried out at $0.04 \mathrm{M} \mathrm{HCl}$. At higher $\mathrm{HCl}$ concentrations there was a decrease in the percentage of transport of $\mathrm{Hg}^{2+}$ ion, probably due to the competition of $\mathrm{H}^{+}$with $\mathrm{Hg}^{2+}$ ion for binding to IIDE and competition of chloride ion with IIDE for complexation with $\mathrm{Hg}^{2+}$ ion. The efficiency of transport decreases at lower $\mathrm{HCl}$ concentrations, probably due to hydrolysis of $\mathrm{Hg}^{2+}$ ion.

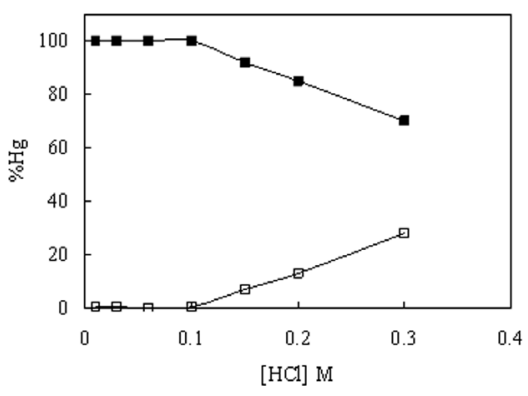

Figure 3. Effect of $\mathrm{HCl}$ concentration in the source solution on the mercury

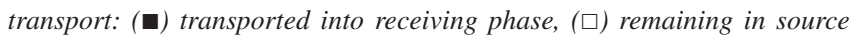
phase. Conditions: $\mathrm{Hg}^{2+}, 2.0 \times 10^{-5} \mathrm{M}$; different concentration of $\mathrm{HCl}$ in source phase; IIDE; $6.0 \times 10^{-3} \mathrm{M}$ in membrane phase and $1.6 \mathrm{M}$ of $\mathrm{SCN}^{-}$in receiving phase after $2.5 \mathrm{~h}$

\section{Effect of ligand concentration}

The preferential binding of sulfur containing ligands towards $\mathrm{Hg}^{2+}$ ion has been reported in the literature. ${ }^{18,19}$ The influence of the concentration of IIDE in the organic phase on the transport efficiency of $\mathrm{Hg}^{2+}$ ion was studied. It was seen that the percentage of transport of $\mathrm{Hg}^{2+}$ ion increases with an increase in IIDE concentration in the organic phase. Maximum transport occurs at concentration range of 0.5 mM-0.04 M IIDE. A further excess of the carrier had no considerable effect on the transport efficiency. Thus, a concentration of 6.0 $\mathrm{mM}$ of IIDE was adopted for further studies. This is most probably due to the fixed stoichiometry of the resultant $1: 1$ carrier- $\mathrm{Hg}^{2+}$ ion complex.

\section{Effect of receiving phase agent}

The nature and composition of the receiving phase was found to have a dramatic influence on the $\mathrm{Hg}^{2+}$ ion transport. Preliminary experiments revealed that the nature and composition of the receiving phase could have a significant effect on the efficiency and selectivity of transport. Among different receiving agents used such as hydrochloric acid, hydrobromic acid, bromide, thiosulfate, sulfuric acid, nitric acid, EDTA and thiocyanate, $\mathrm{SCN}^{-}$ion with increased complexing ability towards $\mathrm{Hg}^{2+}$ ion acts as the most suitable receiver for the release of cation from the membrane phase into the receiving phase.

The influence of the concentration of $\mathrm{KSCN}$ in the receiving phase on the transport efficiency of $\mathrm{Hg}^{2+}$ ion was also investigated and the results are shown in Figure 4. As is obvious, while only $20 \% \mathrm{Hg}^{2+}$ ion transport occurs in the absence of the receiving agent, the transport of $\mathrm{Hg}^{2+}$ ion increases sharply with increasing the concentration of KSCN. Quantitative transport of $\mathrm{Hg}^{2+}$ ion occurs at a $1.6 \mathrm{M}$ of the receiving agent.

The $\mathrm{Hg}^{2+}$ ions form a complex with a deprotonated ionophore to be extracted from the source phase into the membrane phase. The 


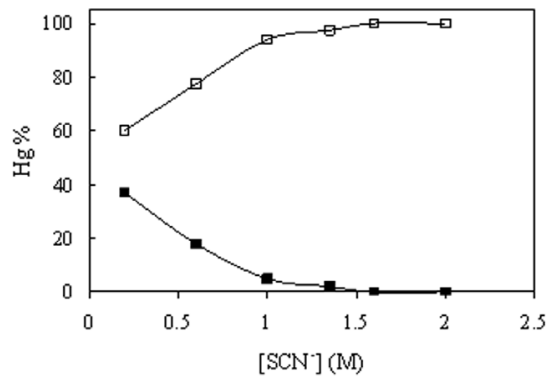

Figure 4. Effect of sodium thiocyanate concentration in the receiving phase solution on the mercury transport: $(\square)$ transported into receiving phase, (ם) remaining in source. Conditions: $\mathrm{Hg}^{2+}, 2.0 \times 10^{-5} \mathrm{M} ; \mathrm{HCl} 0.04 \mathrm{M}$ in source phase; IIDE $6.0 \times 10^{-3} \mathrm{M}$ in membrane phase and various concentration of $S C N^{-}$in receiving phase, after $2.5 \mathrm{~h}$

thiocyanate plays an essential role in the metal ion releasing process in the receiving phase via the formation of a ternary ligand-metalthiocyanate complex which has been reported by other researchers. ${ }^{20-22}$ This co-operation probably assists the selective releasing of $\mathrm{Hg}^{2+}$ ion to the receiving phase, which lead to increase in the percentage of transported $\mathrm{Hg}^{2+}$ ion. Such a ternary complex has already been recognized as being an important transient species in biological transports. ${ }^{23}$

The mechanism of transport in the presence of this carrier could be related to the rapid complex formation and exchange of ions at the membrane interface. In the membrane and receiving phase interface exchange of ligand with thiocyanate for formation of $\mathrm{Hg}(\mathrm{SCN})_{4}{ }^{2-}$ take place. Based on the overall stability constant $\left(\log \beta_{4}\right)$ of $\mathrm{Hg}^{2+}$ ion complexes with respect to $\mathrm{SCN}^{-}$, and $\mathrm{Cl}^{-}$as $\left(\mathrm{Hg}(\mathrm{SCN})_{4}{ }^{2-}, \mathrm{HgCl}_{4}{ }_{4}^{2-}: 20.9\right.$ and $15.1,{ }^{24}$ one may notice that this is consistent with the selectivity order of described procedure. As is known use of thiocyanate ion as a receiving agent effectively avoids the formation of $\mathrm{Hg}(\mathrm{OH})_{2}(\mathrm{~s})$ precipitate. Consequently, this compound was used as a receiving phase agent in our later transport experiments.

\section{Influence of stirring rate}

The effect of stirring speed on $\mathrm{Hg}^{2+}$ ion transport through bulk liquid membrane was investigated. The effect of stirring rate of organic phase in the range of 50-500 rpm on the $\mathrm{Hg}^{2+}$ ion transport efficiency was also studied. The results revealed that replicate transport occur in the stirring rate about $300 \mathrm{rpm}$. The experimental data indicate that beyond $300 \mathrm{rpm}$ the flux of $\mathrm{Hg}^{2+}$ ions through the bulk liquid membrane becomes independent of the stirring rate. In higher rates more than $400 \mathrm{rpm}$, some mixing of source phase and receiving phase will occur. In receiving phase rate of $300 \mathrm{rpm}$ the thickness of the aqueous diffusion films reaches a constant limiting value. Consequently, all subsequent experiments were carried out at a stirring rate of $300 \mathrm{rpm}$ in the source and receiving phase solutions.

\section{Effect of time}

Additionally, the concentration-time profile of $\mathrm{Hg}^{2+}$ ion transport was studied. Figure 5 shows a rapid rise in metal concentration in the receiving phase as well as a sharp decrease in $\mathrm{Hg}^{2+}$ ion concentration in the source phase during the first 120 min of transport and most of $\mathrm{Hg}^{2+}$ ions in source phase evacuated but residual complexes in the membrane will slowly transport to receiving phase. However, the release of $\mathrm{Hg}^{2+}$ ions from the membrane into the aqueous receiving phase occurs at a slower rate. It was confirmed under optimal conditions more than $97 \%$ of $\mathrm{Hg}^{2+}$ ions were transported from the source phase into the receiving phase after $2.5 \mathrm{~h}$.

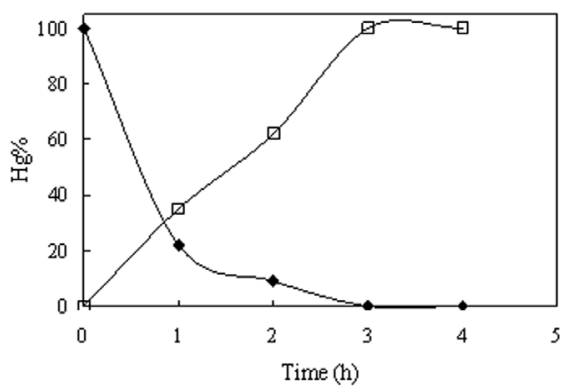

Figure 5. Effect of time on the mercury transport: $(\square)$ transported into receiving phase, $(\mathbf{\square})$ remaining in source. Conditions: $\mathrm{Hg}^{2+}, 2.0 \times 10^{-5} \mathrm{M} ; \mathrm{HCl}$ $0.04 \mathrm{M}$; thiocyanate $1.6 \mathrm{M}$; IIDE $6.0 \times 10^{-3} \mathrm{M}$

\section{Selectivity}

The selectivity of the membrane system in tertiary mixture was studied at optimum conditions for the transport of $\mathrm{Hg}^{2+}$ ion with respect to other cations which were initially present with in equimolar concentrations.

Table 1 shows the percentage of cations transported into receiving phase and remained in source phase. High stability constant of $\mathrm{Hg}^{2+}$ ion with IIDE and thiocyanate ion in membrane and receiving phase largely improved the method selectivity.

Table 1. Amount of cation transported from different cation mixtures through the BLM

\begin{tabular}{lccc}
\hline Mixture & $\begin{array}{c}\text { Percentage } \\
\text { transported }\end{array}$ & Mixture & $\begin{array}{c}\text { Percentage } \\
\text { transported }\end{array}$ \\
\hline $\mathrm{Hg}^{2+}$ & 98 & $\mathrm{Hg}^{2+}$ & 98 \\
$\mathrm{~Pb}^{2+}$ & 0 & $\mathrm{Co}^{2+}$ & 0 \\
$\mathrm{Cd}^{2+}$ & 0 & $\mathrm{Ni}^{2+}$ & 0 \\
$\mathrm{Hg}^{2+}$ & 98 & $\mathrm{Hg}^{2+}$ & 97 \\
$\mathrm{Cr}^{3+}$ & 0 & $\mathrm{Cu}^{2+}$ & 1 \\
$\mathrm{Tl}^{+}$ & 0 & $\mathrm{Zn}^{2+}$ & 0 \\
$\mathrm{Hg}^{2+}$ & 97 & & \\
$\mathrm{Ag}^{+}$ & 12 & & \\
$\mathrm{Fe}^{3+}$ & 4 & & \\
\hline
\end{tabular}

aConditions: source solution, $5 \mathrm{~mL}$ of $2.0 \times 10^{-5} \mathrm{M} \mathrm{Hg}^{2+}, 2.0 \times 10^{-5} \mathrm{M}$ of other cations and $0.04 \mathrm{M} \mathrm{HCl}$ in source phase $0.006 \mathrm{M}$ IIDE in Membrane and 1.6 $\mathrm{M} \mathrm{SCN}^{-}$in receiving phase.

As can be seen from Table 1 , after $2.5 \mathrm{~h}, \mathrm{Hg}^{2+}$ ions were almost completely transported through the chloroform membrane from the source phase into the receiving phase. Meanwhile, most of the other metal ions used, even $\mathrm{Cu}^{2+}$ which is known to have affinity for this sulfur containing ligand, were hardly transferred through the membrane. The observed selectivity pattern toward $\mathrm{Hg}^{2+}$ ion is due to the high tendency of the cation, as a soft acid, towards donating sulfur atoms of the carrier as soft bases.

\section{Recommended mechanism}

The recommended mechanism for the transport of $\mathrm{Hg}^{2+}$ ion through bulk liquid membrane, which operated in this study, is shown schematically in Figure 6. Movement of the charged species through the hydrophobic organic membrane is accomplished by the presence of host carrier IIDE ion paired with chloride as a suitable counter 
anion. The chloride ion not only neutralizes the charged $\mathrm{Hg}^{2+}-\mathrm{IIDE}$ complex but also induces a more lipophilic character to the mercury complex so that it can be readily extracted into the membrane phase. After complexation of $\mathrm{Hg}^{2+}$ ion with carrier on the source side of the membrane, the complex diffuses down its concentration gradient. On the receiving side of the membrane, the metal ion is released into the receiving phase via formation of a ternary complex (carrier- $\left.\mathrm{Hg}^{2+}-\mathrm{SCN}\right)$. Then the free carrier diffuses back across the membrane and cycle starts again. The net result is the transport of $\mathrm{Hg}^{2+}$ ion from the aqueous source phase to the aqueous receiving phase across the BLM.

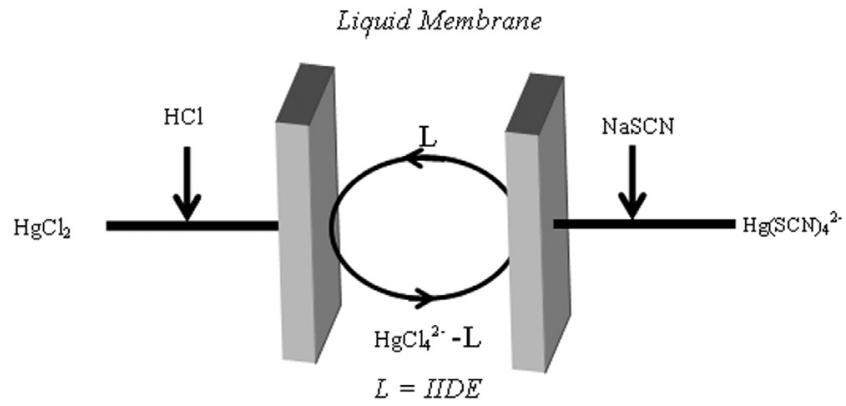

Figure 6. Transport mechanism of Mercury through BLM process

\section{ACKNOWLEDGEMENT}

We thank the Yasouj and Razi universities for financial support

\section{REFERENCES}

1. Foo, S. C.; Tan, T. C.; Sci. Total Environ. 1998, 209, 185; Tuzen, M.; Soylak, M.; Bull. Environ. Cont. Tox. 2005, 74, 968.

2. Ghaedi, M.; Fathi, M. R.; Shokrollahi, A.; Shajarat, F.; Anal. Lett. 2006, 39, 1171.

3. Fakhari, R.; Khorrami, A. R.; Shamsipur, M.; Sep. Pur. Technol. 2006, 50,77 .
4. Ma, M.; He, D. S.; Liao, S. H.; Zeng Y.; Xie, Q. J.; Yao, S. Z.; Anal. Chim. Acta 2002, 456, 157.

5. Ma, M.; Chen, B.; Luo, X. B.; Tan, H.; He, D. S.; Xie, Q. J.; Yao, S. Z.; J. Membr. Sci. 2004, 234, 101.

6. Shukla, J. P.; Kumar, A.; Singh, R. K.; Indian J. Chem. 1992, 31A, 7373.

7. Cleij, M. C.; Scrimin, P.; Tecilla, P.; Tonellato, U.; J. Org. Chem. 1997, 62, 5592.

8. Ghaedi, M.; Akhond, M.; M. Sc. Thesis, Shiraz University, 1996

9. Ikeda, I.; Yamazaki, H.; Konishi, T.; Okahara, M.; J. Membr. Sci. 1989, $46,113$.

10. Vohra, D. K.; Sharma, A.; Indian J. Environ. Prot. 1989, 9, 769.

11. Izatt, R. M.; Jones, M. B.; Lamb, J. D.; Bradshaw, J. S.; Christensen, J. J.; J. Membr. Sci. 1986, 26, 241.

12. Bromberg, L.; Lewin, I.; Warshawsky, A.; Hydrometallurgy 1993, 33, 59.

13. Izatt, R. M.; Lind, F. C.; Bruening, A. L; Bradshaw, J. S.; Lamb, J. J.; Christensen, J. D.; Pure Appl. Chem. 1986, 58, 1453.

14. Shokrollahi, A.; Ghaedi, M.; Ghaedi, H.; J. Chin. Chem. Soc. 2007, 54, 933.

15. Reason, R. G.; J. Am. Chem. Soc. 1963, 85, 3533.

16. Safavi, A.; Shams,E.; J. Mem. Sci. 1998, 144, 37.

17. Ghaedi, M.; Shokrollahi, A.; Montazerzohori, M.; Gharaghani,S.; Acta Chim. Slov. 2006, 53, 428.

18. Moore, M. J.; Distefano, M. D.; Zydousky, L. D.; Cummings, R. T.; Walsh, C. T.; Acc. Chem. Res. 1990, 23, 301.

19. Delaigue, X.; Hasseini, M. W.; Kyritsakas, N.; De Cian, A.; Fischer, J.; J. Chem. Soc., Chem. Commun. 1995, 609.

20. Alguacil, F. J.; Alonso, M.; Sastre, A. M.; J. Mem. Sci.2005, 252, 237.

21. Mashahadizadeh, M. H.; Mohyaddini, R.; Shamsipur, M.; Sep. Pur. Tech. 2004, 39, 161 .

22. Mashahadizadeh, M. H.; Azimi, G. H.; Shamsipur, M.; Sep. Pur. Tech. 2002, 27, 155

23. Sakurai, T.; Nakahara, A.; Inorg. Chem. 1980, 19, 847.

24. Ghaedi, M.; Falah Shojaie, A.; Montazerozohori, M.; Karami, B.; Gharaghani, S.; Electroanalysis 2005, 17, 1746. 